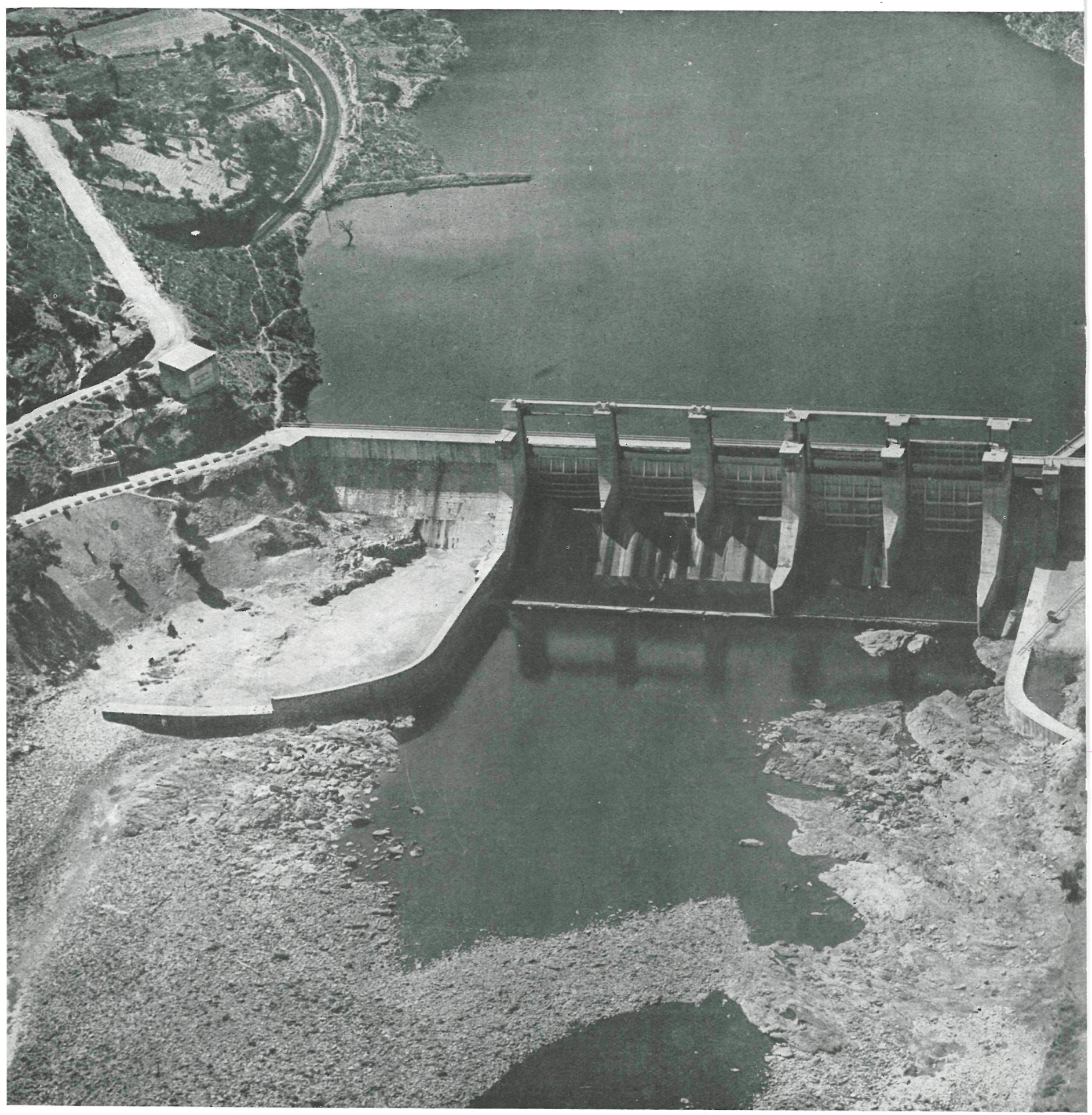

$531 \cdot 30$

\title{
la presa de San Martín y los saltos de Mon
}




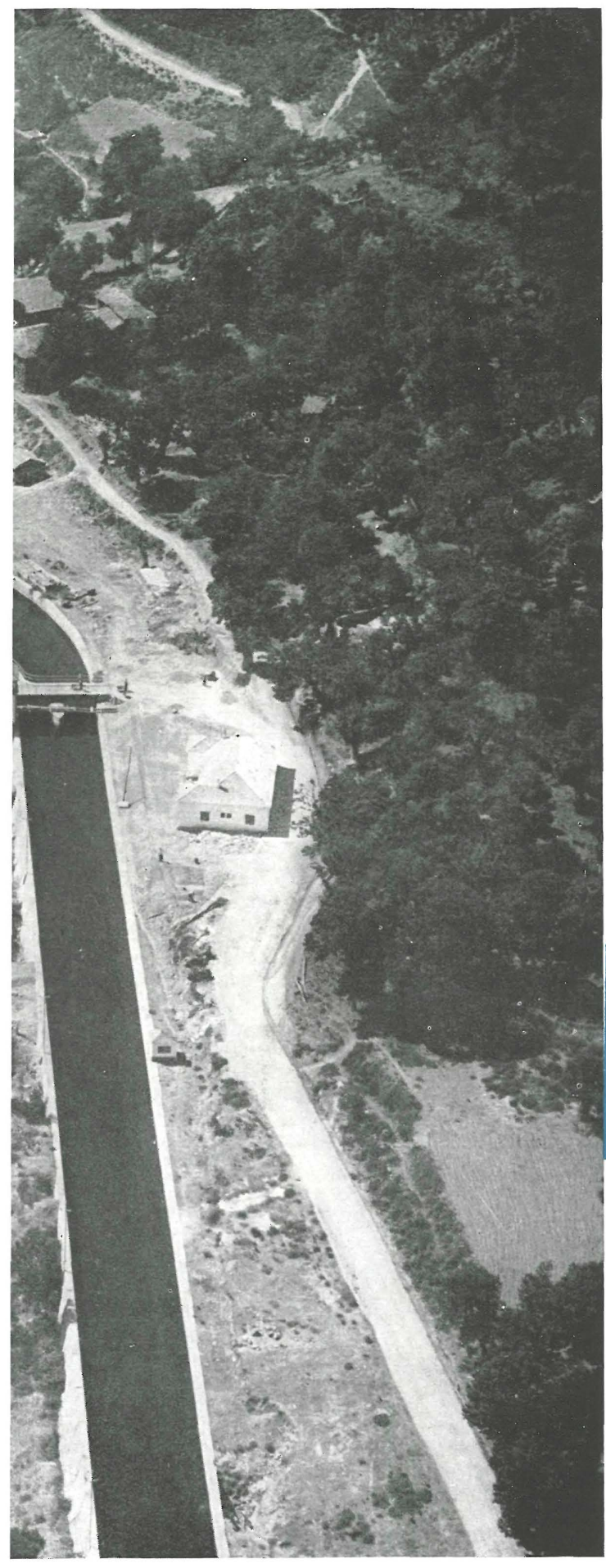

\section{ado y Sequeiros}

S I N O P S I S

En el número 89 de esta revista se describieron las obras de la presa de San Esteban; en el 91, las correspondientes al río presa Saltos del Sil, S. A. viene realizando en la cuenca del Sil y sus afluentes. La presa de derivación de San Martin es también objeto de descripción.

\section{Generalidades}

La cuenca formada por el río Sil y sus afluentes se halla repartida en tres zonas distintas para su explotación, en el triple aspecto de: producción de energía hidroeléctrica, irrigación y como fuente refrigerante de los generadores de energía de las centrales térmicas.

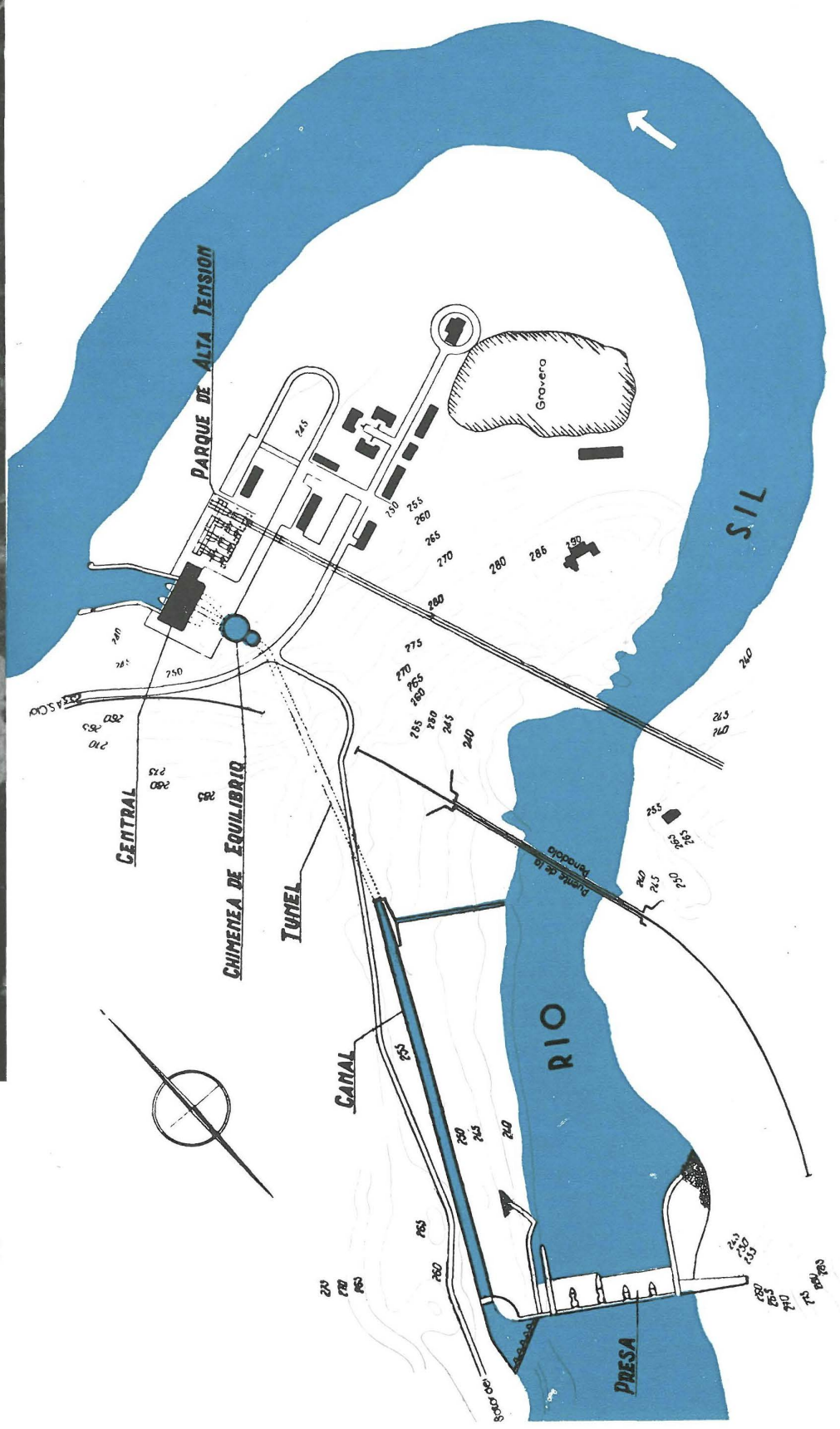


presa de San Martín

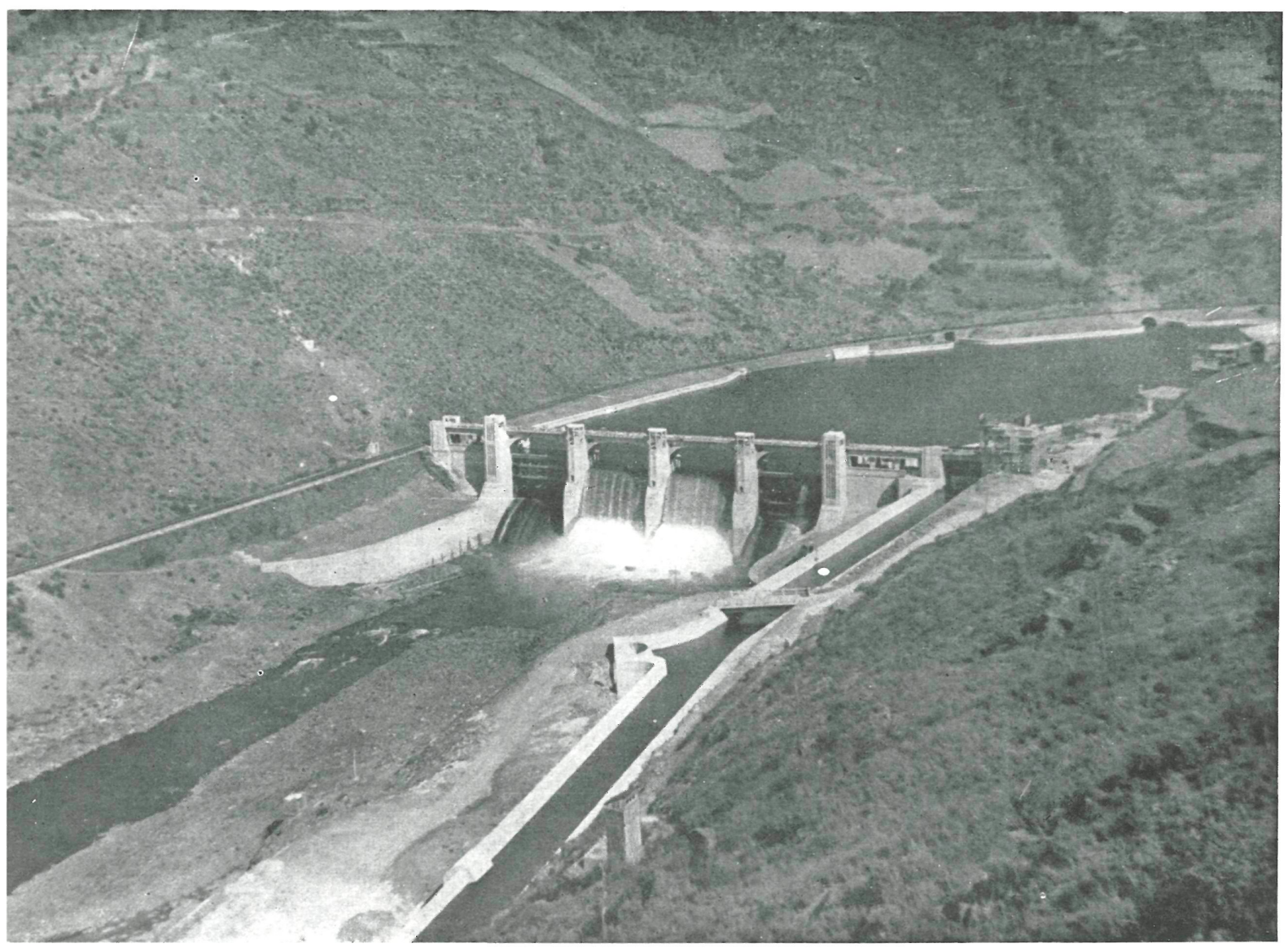

De cada una de estas tres zonas se encarga una empresa distinta de la puesta en explotación y construcción de los distintos aprovechamientos. Así, pues, de Saltos del Sil, S. A., es la sociedad concesionaria para los tramos bajo y medio de la cuenca; la Hidroeléctrica de Moncabril, de los cauces meridionales que aportan sus aguas; y la Empresa Nacional de Electricidad, del tramo medio al alto inclusive.

De las tres obras cuyas características principales son objeto de descripción en este trabajo, la presa de San Martín tiene por objeto la derivación de las aguas del Sil, por medio de un canal, al embalse del aprovechamiento hidroeléctrico de Montefurado, formado con una presa de retención construída sobre el rio Bibey, a cuyo pie se ha emplazado la central generadora. La tercera obra, que es la primera que inició y pusc en explotación Saltos del Sil, S. A., es el saito de Sequeiros, el qual recoge las aguas restituídas por el de Montefurado por medio de una presa de derivación y un canal, parte en galería en carga, que las lleva a la central, situada en la margen de la salida de un pronunciado meandro del río Sil, al que vuelven las aguas después de pasar por las turbinas.

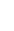

(1)

.


INSTITUTO TECNICO DE LA CONSTRUCCION Y DEL CEMENTO

\section{presa de San Martín}

La presa de San Martín, situada sobre el río Sil, aguas arriba de la confluencia del río Bibey con el Sil, es de tipo gravedad, de unos $24,5 \mathrm{~m}$ de altura, y tiene por objeto derivar las aguas del Sil al embalse de Montefurado, situado en pr Bibey, por medio de un canal de unos cuatro kilómetros de longitud, de una capacidad de $75 \mathrm{~m}^{3} / \mathrm{s}$ y con la coronación de los muros cajeros en un plano horizontal, evitándose así a roul col dependiendo unicamente del desni

Esta presa, de reciente construcción, forma un embalse de $7,2 \mathrm{Hm}^{3}$ de capacidad, de los que se aprovechan tres, en período de aguas bajas, para la regulación diaria.

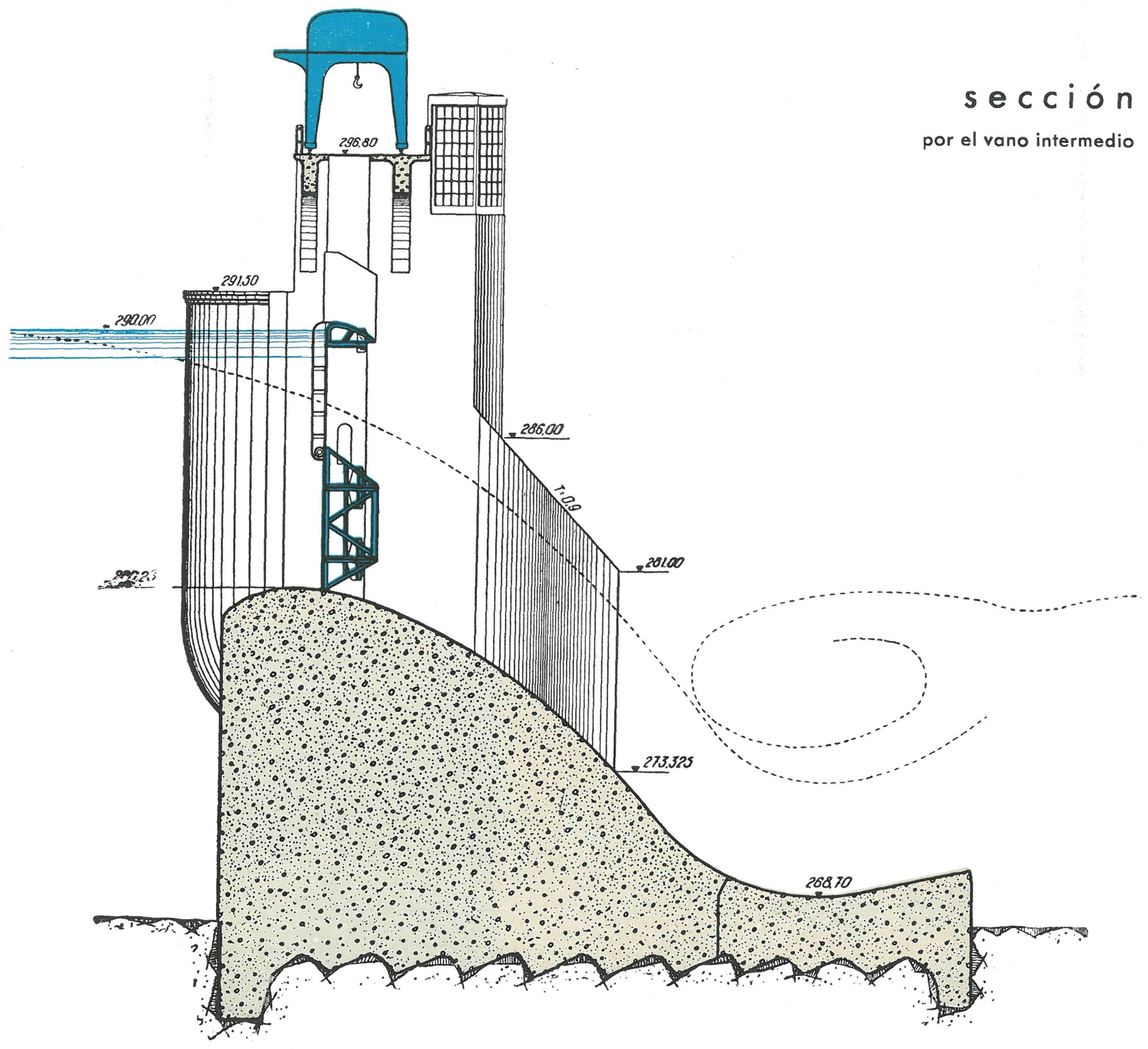




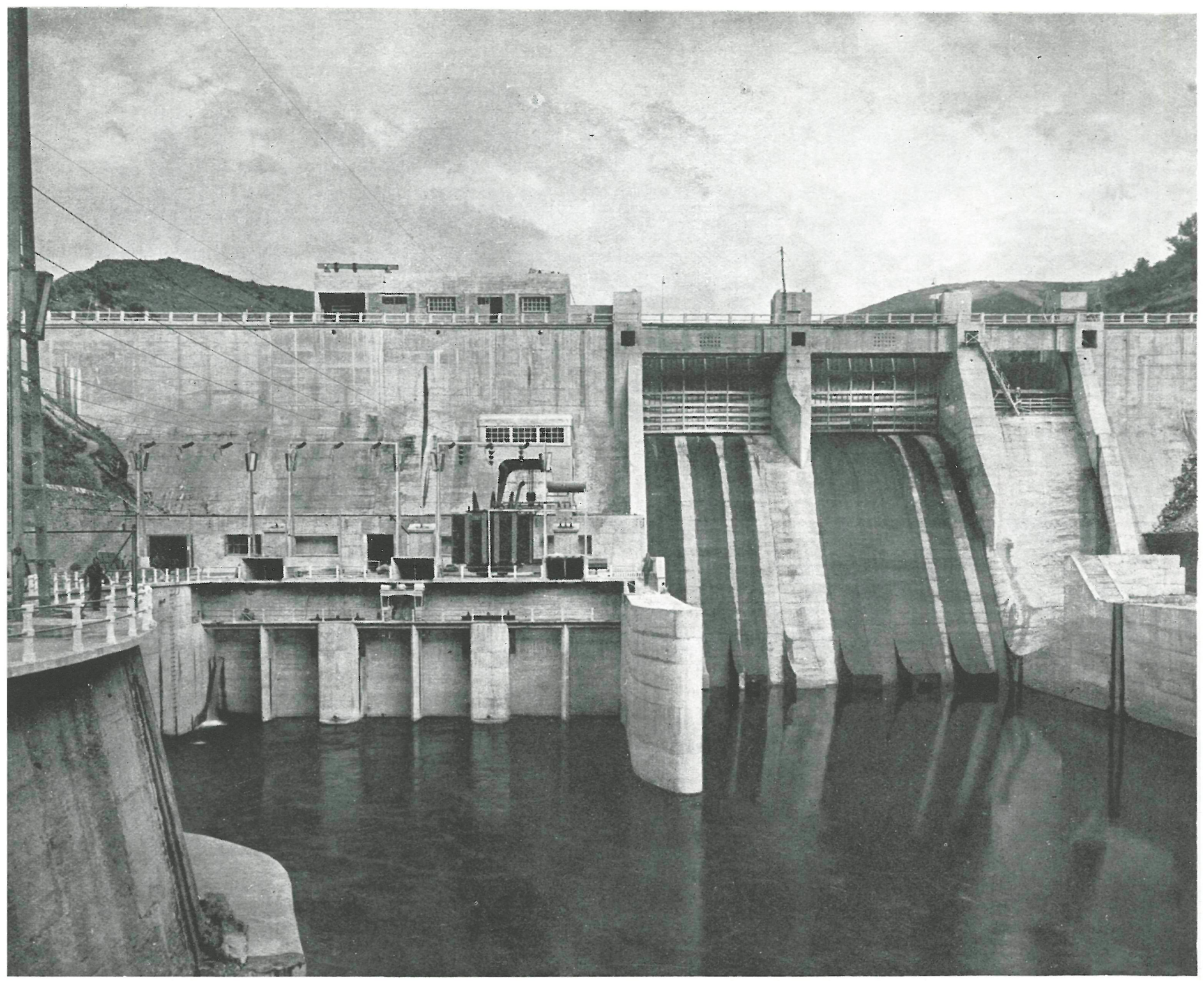

salto de Montefurado

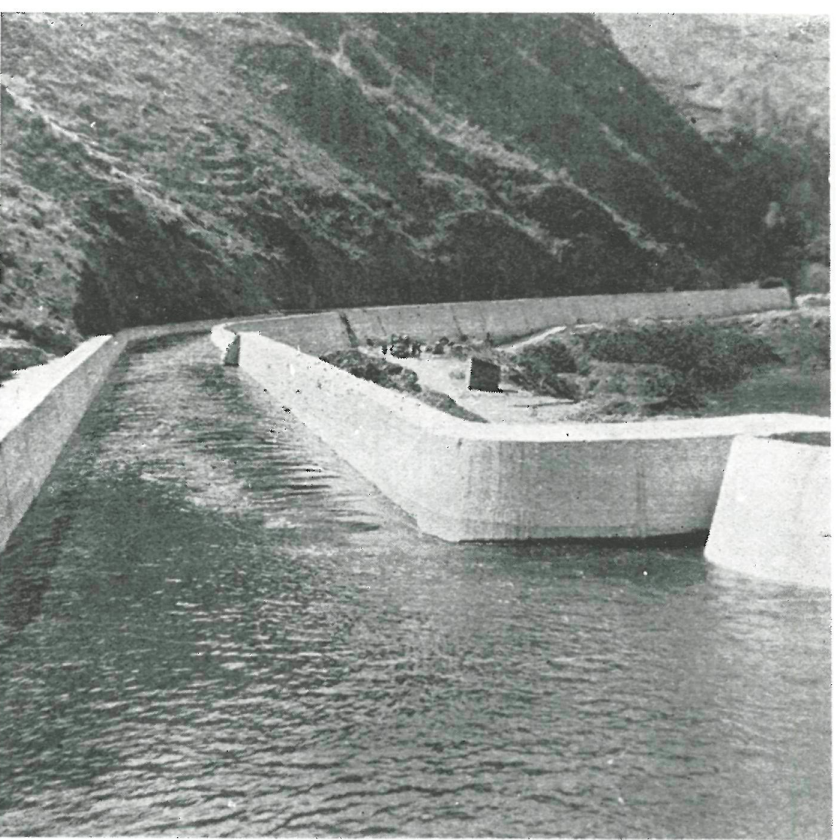




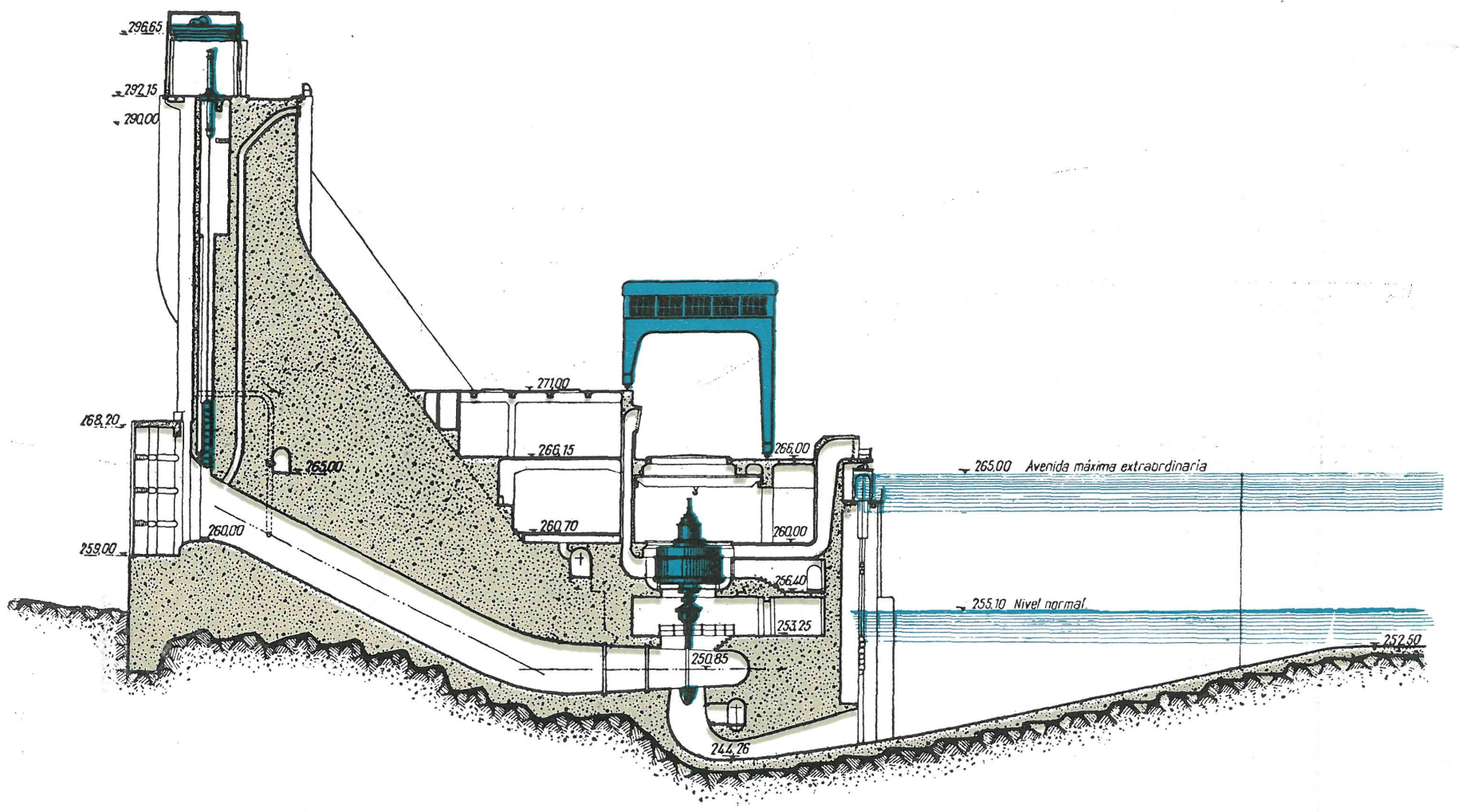

La presa de este aprovechamiento es del tipo de gravedad, de unos $42 \mathrm{~m}$ de altura a partir de la base de cimientos, y está provista de un aliviadero de superficie de $1.800 \mathrm{~m}^{3} / \mathrm{s}$, subdividido en dos compuertas principales de $15 \times 9 \mathrm{~m}$ cada una, y una tercera, de tipo sector, que cierra una superficie de $10 \times 5 \mathrm{~m}$, vertiendo lateralque cierra una superficie de $10 \times 5 \mathrm{~m}$, vertía.
mente en el cuenco destructor de energí.

sección

por la central

La central de este salto es de pie de presa, de unos $56.000 \mathrm{CV}$ de potencia. Está equipada con tres grupos generadores de $18.750 \mathrm{CV}$ de potencia cada uno, que giran a razón de 300 r. p. m. y tienen un gasto de $45 \mathrm{~m}^{3} / \mathrm{s}$ $y$ un salto de $34,8 \mathrm{~m}$.

Como las grandes avenidas se hacen sentir notablemente y no existía gran espacio, la central dispone de un puente-grúa instalado al exterior y se ha elevado su cota dentro de las posibilidades factibles.

\section{Salto de Sequeiros}

Este aprovechamiento está compuesto por una presa de gravedad, de $22,2 \mathrm{~m}$ de altura, provista de un aliviadero de superficie, de $4.000 \mathrm{~m}^{3} / \mathrm{s}$ de capacidad, formado por dos compuertas de $15 \times 10,5 \mathrm{~m}$, tres de $15 \times 8 \mathrm{~m}$ una pequeña, de tipo automático, que sirve para la limpieza superficial del embalse.

El remanso del embalse formado por la referida presa llega hasta el pie de la restitución de aguas de la central de Montefurado.

La presa deriva las aguas a un canal de superficie, que después desciende en forma de galería en carga para llevar las aguas a la central.

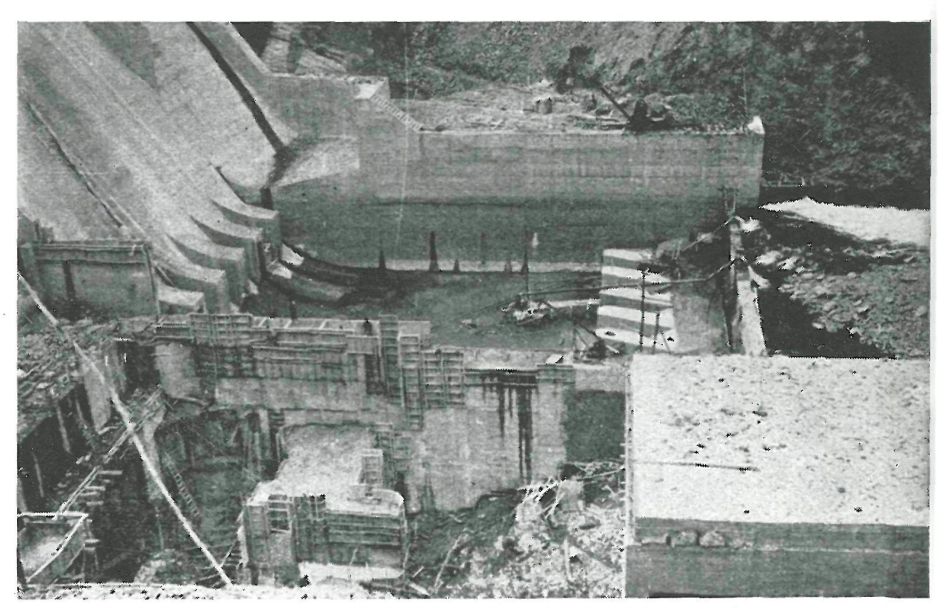




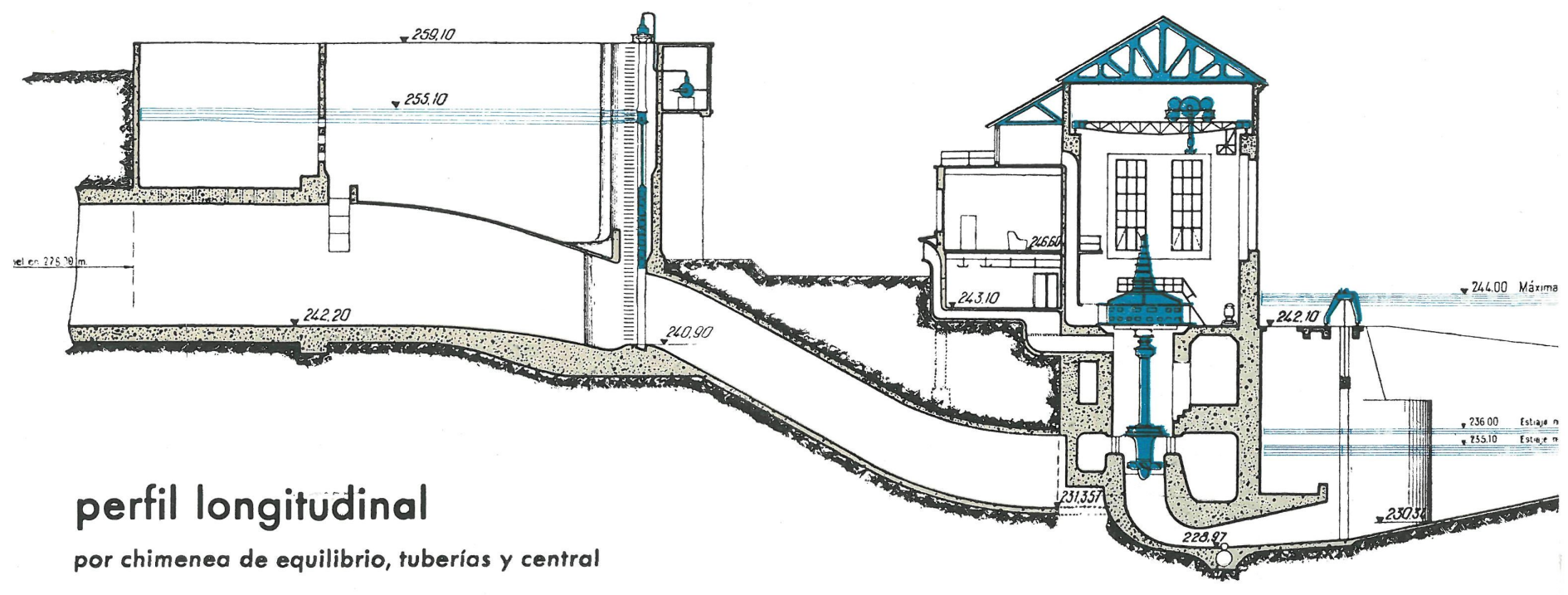

salto de Sequeiros

La central se ha equipado con tres grupos accionados con turbinas Kaplan, que utilizan una caída de 19,1 $\mathrm{m}$ de altura, tienen una potencia unitaria de $8.500 \mathrm{CV}$ y giran a $250 \mathrm{r}$. p. m., junto con sus alternadores de $7.500 \mathrm{KVA}$ de potencia cada uno.

Las aguas utilizadas se restituyen nuevamente al Sil a la salida de un pronunciado meandro que el río forma inmediatamente después de pasar la presa de derivación. J. J. U.
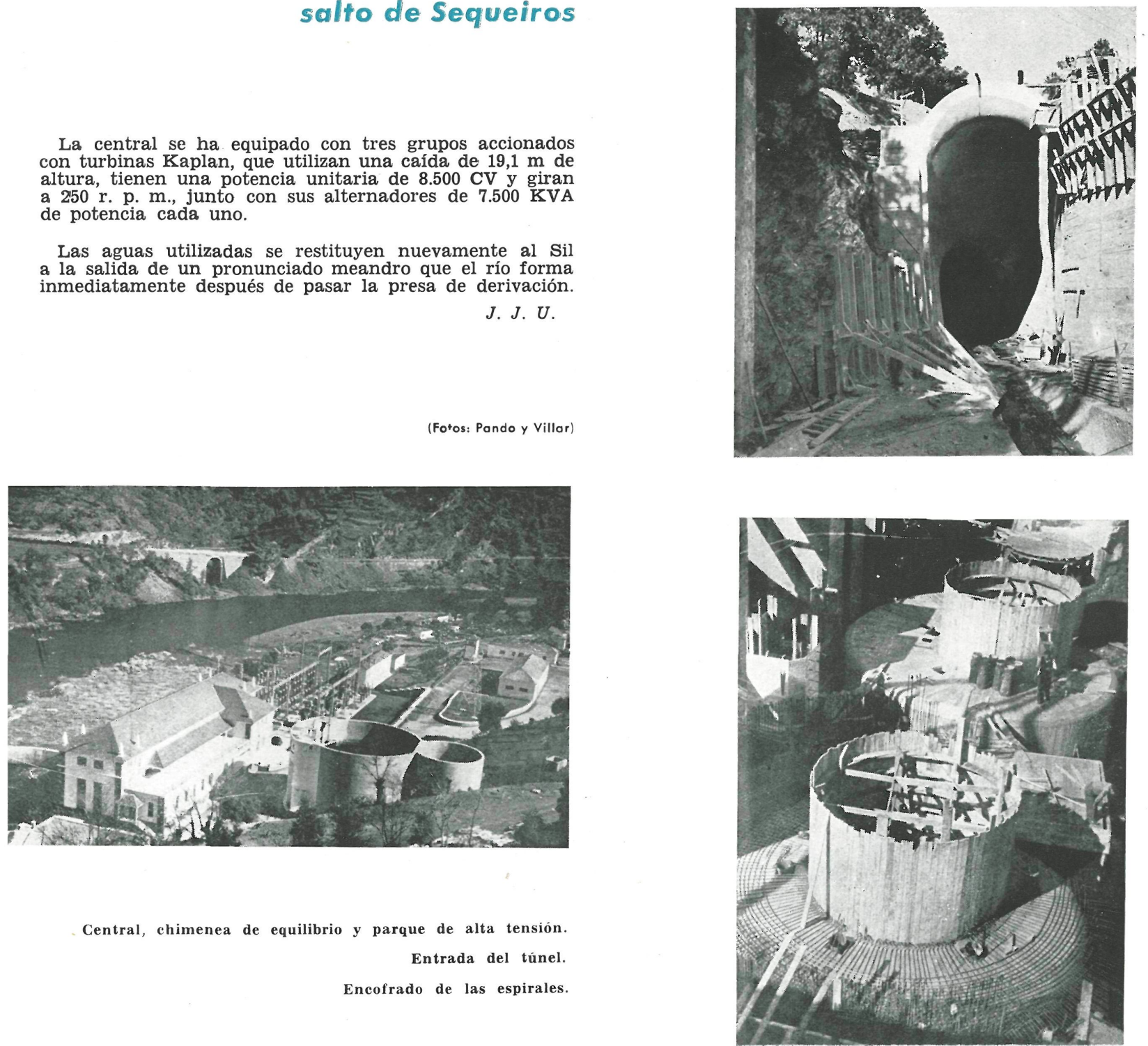